\title{
ANNA KUMARI: MAESTRO SENI TARI DAN SONGKET PALEMBANG
}

\author{
ANNA KUMARI: \\ PALEMBANG TRADITIONAL DANCE AND SONGKET MAESTRO
}

\author{
Ajisman \\ Balai Pelestarian Nilai Budaya (BPNB) Sumatera Barat \\ Jl. Raya Belimbing No 16 A Kuranji Kota Padang \\ E-mail: ajisman.dt@gmail.com
}

\begin{abstract}
Abstrak
Penulisan biografi Anna Kumari bertujuan untuk mengungkap dan menjelaskan pemikirannya tentang tari dan songket tradisional Palembang. Metode yang digunakan adalah metode sejarah, yaitu menjelaskan suatu persoalan berdasarkan perspektif sejarah. Hasil penelitian menunjukkan bahwa sosok Anna Kumari adalah sebagai seorang seni pertunjukan dan koreografer terkemuka di Palembang dimana ia menciptakan tidak kurang dari 50 jenis tarian tradisional dan tarian kontemporer. Karya tariannya tidak hanya tampil di bumi Sriwijaya tapi juga mencapai panggung nasional, bahkan mancanegara. Anna Kumari juga dikenal sebagai penenun Songket Palembang yang terkenal. Usaha menenun awalnya didirikan untuk memenuhi kebutuhan tari dan kemudian pada akhirnya berkembang menjadi industri rumah tangga yang sedang berkembang. Anna Kumari telah menerima banyak penghargaan atas usahanya mempromosikan Songket Palembang, baik dari pemerintah, maupun institusi lainnya
\end{abstract}

Kata kunci: Anna Kumari, Tokoh Maestro, Seni Tari dan Songket

\begin{abstract}
Writing the biography of Anna Kumari aimed to uncover and explain her thought on Palembang traditional dance and songket. Examining one's thought constitutes as one of the works of history, where the method used is historical method, which describes an issue based on a historical perspective. The procedure consists of heuristicism, sources criticism, interpretation, and historiography in form of story. The results show that figure of Anna Kumari is noted as a prominent performing arts and choreographer in Palembang where she creates not less than 50 types of traditional dance and contemporary dance. Her works of dance is not only performed in the earth of Sriwijaya but also reach national stage, and even foreign countries. Anna Kumari is also celebrated as a prominent Palembang Songket weaver. The weaving business is initially established to meet the needs of dance and then it eventually evolves into a growing home industry. She has received numerous awards for her efforts in promoting Palembang songket, either from government, as well as other institutions.
\end{abstract}

Key words: Anna Kumari, Arts Maestro, Dance and Songket 


\section{PENDAHULUAN}

Anna Kumari di lahirkan di Palembang tanggal 10 Nopember 1946 dari keluarga R.A.Amantjik Rozak (mantan Perintis Kemerdekaan RI), Anna Kumari mulai pelajar menari tahun 1961 ketika masih duduk di bangku Sekolah Dasar. Dalam mengembangkan bakatnya tahun 1966 ia mendirikan studio dengan nama "Studio Tari Anna Kumari”. Sanggar tari yang didirikannya mengembangkan beragam tari tradisional dengan mendidik anak-anak muda Palembang. Dalam perkembangannya sanggar Anna Kumari semakin maju dan terkenal pada masanya, sanggar Anna Kumari sering tampil di event-event penting yang dihadiri oleh tamutamu penting di Palembang. Anna Kumari disamping ia berkerja sebagai Pegawai Negeri Sipil di Dinas Pendidikan dan Kebudayaan Kota Pelembang ia juga sebagai penyiar Radio "Rama Samudra" Angkatan Laut Kosumbaksional 304 Palembang, Radioa "Rama Samudra" menyiarkan berbagai macam aktivitas seni di bumi Sriwijaya. Anna Kumari pembina kesenian di Kodam IV Sriwidjaya dan juga aktif dalam kegiatan organisasi Dewan Kesenian Daerah Sumatera Selatan ( Wawancara dengan Anna Kumari, di Kota Palembang, 24 Oktober 2013 ).

Berbagai julukan yang diberikan pada sosok Anna Kumari oleh masyarakat Palembang. Diantaranya ada yang memposisikanya sebagai sosok tokoh seni pertunjukan dan koreografer (pencipta tari). Lebih kurang 50 jenis tari tradisional maupun tari kreasi yang ia ciptakan. Sosok Anna Kumari sebagai seorang koreografer (pencipta tari) tidak diragukan lagi, karyakarya tarinya tidak hanya dipergelarkan di bumi Sriwijaya tapi juga ke pentas nasional. Anna Kumari pernah menjadi penari istana pada masa pemerintahan Soekarno, bahkan hingga mancanegara. Anna Kumari juga pernah mendirikan grup bend yang diberi nama "Ayam Molek" yang semua anggotanya adalah perempuan (Sumatera Pos "Tokoh", Sabtu 16 Mei 2007). Anna Kumari bukan saja mengajar tari di daerah Provinsi Sumatera Selatan, tetapi ia juga mengajarkan tari pada masyarakat Sumatera Selatan yang ada diluar negeri seperti Singapura, Malaysia dan Berunai Darussalam (Berita Buana "Ekonomi \& Keluarga" Kamis 4 Desember 1993). Murid-murid Anna Kumari diberbagai daerah di Sumatera Selatan sudah banyak yang mendirikan sangar-sangar tari, menurut pengakuan Anna Kumari muridnya di Singapura sudah ada yang membuat sangar tari dan masih berkembang sampai sekarang. Tahun 1975 sampai dengan 1990 pada saat masih aktif sebagai Pegawai Negeri Sipil di Depertemen Pendidikan dan Kebudayaan Kota Palembang, Anna Kumari banyak menciptakan tari, berbagai jenis tari hasil ciptaannya sering diperlombakan dikalangan pelajar di Provinsi Sumatera Selatan.

Anna Kumari selain dijuluki sebagai seorang koreografi, tari ia juga dijuluki oleh masyarakat Palembang sebagai seorang tokoh pelopor pembina tenun Songket Palembang, banyak penghargaan yang telah ia terima dari usahanya dalam memajukan tenun songket di Palembang, baik dari pemerintah, maupun dari kalangan instansi lain. Aktivitas Anna Kumari di bidang tari tidak terlepas dari tenunan songket khususnya Songket Palembang. Karena kain songket merupakan salah satu penunjang grup tari, jika tampil untuk menari memerlukan pakaian corak songket yang bervariasi. Bagi Anna Kumari antara tari dan songket tidak bisa dipisahkan, pakaian yang dipakai oleh sang penari selain untuk elok dipandang juga sangat menunjang kepercayaan diri para penari untuk tampil lebih sempurnah. 
Anna Kumari berkecimpung dalam tenun songket diawali ketika ia mulai membuka "Sanggar Anna Kumari”. Dimana setiap menghadiri undangan untuk menari di berbagai event memerlukan pakaian tari yang bervariasi. Pada awalnya ia memakai pakaian songket tua warisan keluarganya, karena sering dipakai tentu lama-kelamaan songket tua warisan orang tuanya akan rusak. Mengingat kebutuhan untuk pakaian tari ini, maka Anna Kumari mengembangkan tenun songket yang sudah dirintis oleh kedua orang tua sebelumnya, sehingga kebutuhan untuk pakaian tari dapat terpenuhi. Usaha tenun pada awalnya hanya untuk kebutuhan tari akhirnya berkembang menjadi home industri. Tahun 1980 an di kawasan rumahnya di Jalan K.H.A. Azhari No. 14 Ulu Palembang home industri Anna Kumari sudah memiliki 75 penenun yang menghasilkan berbagai jenis motif songket ( Sumatera Express, Kamis 23 Agustus 1990 ).

Dalam perkembangannya songket produksi Anna Kumari tidak hanya memproduksi pakaian untuk menari, akan tetapi juga memproduksi berbagai jenis songket yang banyak diminati oleh berbagai kalangan, baik dalam negeri maupun mancanegara. Hume Industri Anna Kumari mengikuti berbagai event pameren, baik tingkat nasional maupun internasional seperti Singapura, Malaysia, Berunai Darussalam, Hongkong, Amerika, Jeddah dan Dubai. Berbagai penghargaan yang ia peroleh dari hasil karyanya sebagai pencipta tari dan pelopor tenun songket Palembang. Antara lain penghargaan yang ia peroleh adalah: Penghargaan di bidang seni dari Pemerintah Singapura pada tahun 1991, Penghargaan Upakarti atas kepeloporanya sebagai pengusaha kerajinan songket tahun 1993 dari Pemerintah Republik Indonesia, dan Penghargaan Wanita Citra Pembangunan dari Pemerintah Republik Indonesia tahun 2004. Selain itu, dia sudah menciptakan lebih dari 50 tarian, baik tari tradisional maupun tari kreasi ( Catatan Anna Kumari, tanggal 14 Nopember 2012).

Berbagai pandangan dan julukan yang di berikan masyarakat Palembang pada sosok Anna Kumari, membuat tokoh ini menjadi tokoh yang kontroversi di kalangan masyarakat Palembang. Dikatakan sebagai tokoh maestro seni tradisi, khususnya seni pertunjukan karena banyak menciptakan tari tradisional maupun tari kreasi. Tidak jarang juga masyarakat Palembang yang mengatakan bahwa Anna Kumari adalah salah seorang tokoh pelopor pembina tenun Songket Palembang.

Dalam menanggapi pendapat yang meragukan ia sebagai tokoh kareografer tari dan pelopor pembina tenun Songket Palembang, perlu pembuktian secara mendalam. Upaya ini perlu diangkat dan ditelusuri guna membuktikan keabsahan pandangan tersebut. Jika ditelusuri dari beberapa hasil karya tentang tari dan keterlibatanya dalam aktivitas seni dan tenun Songket Palembang, maka ia layak dikatakan seorang tokoh maestro seni tradisi dan pelopor tenun songket Palembang. Asumsi ini dilatar belakangi dari data yang ada, bahwa ternyata dalam lintasan sejarah kehidupanya, ia merupakan seorang tokoh kareografer tari dan pelopor tenun Songket Palembang yang berkiprah selama lebih kurang 65 tahun sampai sekarang. Anna Kumari juga telah menularkan bakat seninya kepada anak-anaknya antara lain putranya yang sudah berhasil ia didik: Mirza Indah Dewi berprofesi sebagai guru tari dan juga sudah punya sanggar tari, anak lelakinya Farhan Segentar Alam memiliki "Bend Segentar Alam". Bend ini sangat terkenal dalam mengiringi tari tarian di Kota Palembang. Bertolak dari realita inilah yang menjadi faktor pemilihan tema penelitian ini. Dari hasil penulisan biografi seorang tokoh, 
diharapkan adanya contoh-contoh sikap dan perilaku dari tokoh yang diangkat, yang dapat dijadikan suri teladan bagi kehidupan sekarang. Misalnya sikap kepemimpinan, keterbukaan, kreativitas, kewibawaan, kebijaksanaan, keberanian, kejujuran dan pengabdian (Suwadji Syafi'i 1984:7)

Secara teoritis ada tiga bentuk biografi, yaitu biografi interpretatif, biogragafi populer, dan biografi sumber (RZ. Leirissa 1984:97). Sementara (Sartono Kartodirjo 1994:76) mengatakan biografi adalah kisah hidup seseorang yang benar-benar terjadi, yang meliputi segenap ikhwal mengenai pribadi seseorang dalam lingkungan hidupnya. Biografi interpretatif adalah biografi yang selain memperhatikan keseimbangan dalam hal watak, tindakan, perbuatan dan zamannya, juga menganalisa sumber-sumber sejarah, biografi populer biasanya ditulis dengan mempertimbangan komersial, agar lekas laku dipasaran dan penulisan biografi ini tidak selalu mementingkan kebenaran ilmiah. Berbagai gaya retorika dipergunakan untuk menjadikan tokoh itu menarik, sedangkan Biografi sumber pertama yang pernah ditulis mengenai seorang tokoh. Dengan memperhatikan jenis-jenis biografi tersebut, maka penulisan biografi Anna Kumari adalah jenis biografi Interpretatif.

\section{METODE PENELITIAN}

Penelitian ini menggunakan metode penelitian sejarah yang terdiri dari empat tahap. Pertama heruistik mencari dan menemukan sumber-sumber, atau pengumpulan sumber. Kedua kritik, menilai otentik atau tidaknya sesuatu sumber dan seberapa jauh kredibilitas sumber. Ketiga, sintesis dari fakta yang diperoleh melalui kritik sumber atau disebut juga kredibilitas sumber itu dan keempat, penyajian hasilnya dalam bentuk tulisan.(Kuntowijoyo 1999: 89.

Tahap petama, heuristik, tahap mencari dan mengumpulkan data. Data yang diperoleh akan diklasifikasikan menjadi dua, yaitu data primer dan data sekunder. Data primer yang berhubungan dengan informasi dari pelaku atau orang yang sezaman dengan peristiwa yang terjadi. Sedangkan data sekunder adalah informasi dari orang yang bersangkutan dan orang yang dianggap tahu tentang pemikiran Anna Kumari mengenai tari dan perjuangannya dalam memajukan industri songket di Palembang.

Pengumpulan data dilakukan melalui pertama, studi kepustakaan. Studi kepustakaan dilakukan untuk mencari literatur yang berhubungan dengan penelitian ini, yaitu buku-buku, dokumen, arsip, laporan penelitian, artikel atau berita dalam koran, majalah dan lain-lain yang berhubungan dengan Anna Kumari. Kedua, wawancara yang dilakukan dengan mengajukan pertanyaan-pertanyaan kepada yang bersangkutan atau informan lain antara lain keluarga, teman dekat dan orang yang dianggap tahu mengenai Anna Kumari.

Tahap kedua, kritik, yaitu tahap penyeleksian sumber-sumber sejarah. Meliputi kritik eksteren dan intern. Kritik ekstern dilakukan untuk menguji tingkat keabsahan sumber (otentisitas sumber). Sedangkan kritik intern dilakukan untuk menguji kredibilitas sumber apakah sumber itu bisa dipercaya atau tidak. Tahap ketiga adalah tahap analisis dari fakta yang diperoleh melalui kritik sumber atau disebut juga kredibilitas sumber itu.. Dalam hal ini juga adanya interpretasi 
dalam arti merangkaikan fakta-fakta lain menjadi satu kesatuan pengertian. Tahap ini, melakukan analisa berdasarkan fakta sejarah.

Tahap keempar, historiografi, yaitu tahap penulisan sejarah. Pada tahap terakhir ini akan dilakukan koreksi baik secara bertahap maupun secara total. Metode koreksi bertahap dan koreksi total diterapkan guna menghindari kesalahan-kesalahan yang sifatnya subtansial dan akurat sehingga mengahsilkan penulisan sejarah yang dapat dipertanggungjawabkan secara ilmiah.

\section{PEMBAHASAN}

\section{Latar Belakang Keluarga dan Pendidikan \\ Lahir Dari Kelurga Pejuang}

Anna Kumari yang dipanggil Cek Anna, lahir dalam keluarga pejuang yang lahir tanggal 10 Nopember 1945 di 9 Ulu kampung Sungai Aur Kota Palembang. Nama ayahnya A.R Amantjik Rozak, salah seorang pejuang di daerah Palembang. Ketegasan dan kejujuran sang ayah tampaknya begitu kuat tertanam dalam diri Anna Kumari. Dibalik sikap tegas itu, kemampuan senipun secara sengaja diajarkan pada Anna Kumari. Menurut Anna Kumari di tempat ia dilahirkan di 9 Ulu kampung Sungai Aur Palembang adat istiadat sangat kuat dan tradisi itu masih kental pada masyarakat, terutama pantun, syair, dogeng dan cerita-cerita rakyat. Dalam keturunan Anna Kumari masih suka bercerita atau mendogeng yang diwarisi dari nenek moyangnya, ia mengaku jika neneknya menidurkan Anna Kumari diawali dengan mendogeng dan berpantun, maka Anna Kumari pernah memenangkan lomba dogeng tingkat nasional.

A.R Amantjik Rozak yang hanya tamat sekolah MULO, sejak semasa remaja telah giat berjuang melawan penjajah, sikap tersebut terlihat dalam perjuangannya. Dalam usia yang sangat muda, Amantjik Rozak yang lebih dikenal dengan "Pak Sabil", telah mendirikan sekolah untuk warga di kampungnya di 14 Ulu (sekarang masuk dalam kawasan Seberang Ulu II Palembang). Lewat Islamic School yang didirikannya, Amantjik Rozak mengajarkan semangat perjuangan. Selain membebaskan warga kampung dari buta huruf, perlawanan terhadap penjajah juga dilakukan lewat pengajaran lagu-lagu dan syair karangan sendiri. Lagu dan syair tersebut isinya menjelek-jelekan Belanda dan memuji-muji Indonesia.

Perlawanan yang dilakukan lewat pengajaran lagu-lagu dan syair, membuat Amantjik Rozak pernah ditahan selama tiga bulan, sekolah dibuka kembali setelah Amantjik Rozak keluar dari tahanan. Namun akhirnya sekolah itu ditutup secara permanen oleh pihak Belanda (Ismail Djalili dkk 2003:89). Masa perjuangan mengangkat senjata, Amantjik Rozak menjadi Komandan Pasukan Sabilillah Andalas Selatan. Dalam masa perjuangannya itulah putra putrinya lahir. Anna Kumari anak yang ketiga bersaudara, Anna Kumari lahir saat perjuangan mempertahankan kemerdekaan begitu gencar, yaitu tanggal 10 Nopember 1945. Anak yang pertama bernama $\mathrm{Hj}$ Nuraini (telah meninggal dunia), anak ke dua Nurleli (ibu rumah tangga), anak yang ketiga Anwar Puadi lahir tahun 1947 tinggal di Jakarta, kemudian anak ke empat Huriah Iriani (karyawan pertamina). Amantjik Rozak yang lebih dikenal dengan panggilan Pak Sabil, pensiun dari pegawai Negeri Sipil tahun 1951. 


\section{Riwayat Pendidikan}

Sekolah Dasar Anna Kumari dimasukan ke SD Negeri No.5 di Sepuluh Ulu Sungai Aur Palembang. Waktu Sekolah Dasar, Anan Kumari termasuk anak yang rajin dan cerdas serta bersemangat. Dalam beberapa mata pelajaran Anna Kumari unggul dari teman-temannya seperti mata pelajaran kesenian dan keterampilan. Tamat dari Sekolah Dasar, Anna Kumari dimasukan oleh orang tuanya ke Sekolah Menegah Pertama SMP Muhammadiyah Bukit Kecil Palembang, saat sekolah di SMP Muhammadiyah itu Anna Kumari pindah ke kampung ayahnya yang dulunya dinamakan Guguk Tuan Kapar (sekarang Jl. KH Azhary No.14, Kelurahan 14 Ulu Palembang). Ketika sekolah di SMP Muhammadiyah, bakat menari dan bernyanyi masih berjalan terus. Ketika masa libur sekolah, Anna Kumari sering diajak ke Jakarta oleh Hj. Nuraini yang tinggal di Setia Budi Jakarta. Sekitar tahun 1970 an, ketika berlibur di Jakarta dimanfaatkan oleh Anna Kumari untuk belajar tari Bali bersama Iwayan Linggih dan Nyoman Suarni.

Setelah tamat dari SMP Muhamdiyah Bukit Kecil Palembang, Anna Kumari dimasukan oleh orang tuannya ke Pendidikan Sekolah Musik Sriwijaya Palembang. Menurut Anna Kumari yang mengajar di Sekolah Musik Sriwijaya gurunya tamatan Eropa yang bernama Diadungga. Namun sekolah tersebut hanya berjalan satu kali tamatan saja, karena gurunya pergi ke Jakarta, maka sekolah tersebut tidak berjalan lagi. Anna Kumari melanjutkan pendidikannya di Akademi Da'wah Palembang, setelah mengikuti kuliah selama tiga tahun akhirnya Anna Kumari dapat menamatkan pendidikanya di Akademi tersebut. Selain pendidikan formal untuk memperkaya dirinya dengan keterampilan Anna Kumari memasuki beberapa kursus, seperti kursus kecantikan, tata rias wajah, rambut dan pengantin, bahkan di rumahnya ia pernah membuka salon kecantikan, namun setelah berkeluarga aktivitas salon terhenti.

\section{Mulai Belajar Menari dan Bernyanyi}

Masa kecil di kampung yang banyak membentuk watak Anna Kumari. Sejak kecil, Anna sering diajak pergi ke kondangan (menghadiri undangan), Anna sering menyaksikan prosesi rangkaian pelaksanaan adat perkawinan di kampungnya. Apa yang disaksikan dalam adat perkawinan tersebut akan menjadi pengalaman bagi batinya. Perjalanan batin yang panjang yang menempanya, akan memaknai jiwa seninya. Pak Sabil (panggilan Aba Anna Kumari) sangat cermat membawa bakat dan kemampuan anak-anaknya.

Di bawah rumah panggung di Sungai Aur, 9 Ulu Palembang, Anna Kumari kecil bersama teman-teman sebayanya bermain berbalas pantun. Pantun-pantun yang diajarkan ibunda, menjadikannya lincah bersilat kata. Kemampuan Anna Kumari dibidang seni dari kecil didukung lagi oleh Abanya yang pandai bermain gitar, sementara nenek Maryan Dariani (dari sebelah ibu), yang punya grup musik gambus, yang sering mengajari Anna Kumari bermain alat musik.

Aba Anna Kumari, Amantjik Rozak adalah orang yang paling mendukung kecintaan Anna Kumari pada seni. Amantjik Rozak tidak hanya memberikan teori dan praktek bermain musik, Amantjik pun membekali putrinya dengan buku kumpulan lagu dan syair. Yang paling diingat oleh Anna Kumari, lagu berjudul Angin Sampaikan Salamku. Cerita yang paling sering diperdengarkan, Syair Selendang Delimo. Masih duduk di bangku Sekolah Dasar, di kampung 
ibunya, Anna Kumari sudah mulai mengenal panggung. Selain sering diajak untuk menghadiri undangan, Anna kecil telah akrab dengan pertunjukan musik ketika ada acara pesta di kampungya. (Ismail Djalili dkk 2003:91).

\section{Bekerja Sambil Menyalurkan Hoby}

Anna Kumari dingakat menjadi Pegawai Negeri Sipil tahun 1964, ia ditempatkan di Dinas Pendidikan dan Kebudayaan Kota Palembang. Awalnya ia diterima sebagai pegawai Negeri Sipil adalah, ketika ia diutus oleh Dinas Pendidikan dan Kebudayaan Provinsi Sumatera Selatan ke Jakarta untuk mengikuti festival tari pergaulan. Ketika pulang ke Palembang ia diberi surat rekomendasi dari Kementerian Pendidikan dan Kebudayaan di Jakarta. Surat tersebut dialamatkan ke Kepala Insfeksi Kebudayaan Kota Palembang (yang sekarang Dinas Pendidikan Kebudayaan Kota Palembang), yang isinya agar Anna Kumari diterima di kantor Insfeksi Kebudayaan Kota Palembang.

Pada saat Anna Kumari berkerja di Insfeksi Kebudayaan, ia agak jarang masuk kantor, karena kegiatannya lebih banyak di lapangan. Pada waktu bertugas di Insfeksi Kebudayaan itulah Anna Kumari sering mengadakan lomba tari massal. Anna Kumari sadar bahwa seorang Penilik Kebudayaan tidak harus terus berada di kantor. Menurut Anna Kumari untuk menampilkan tari mssal membutuhkan waktu dua sampai tiga bulan. Setiap akan diadakan tari massal Anna Kumari merancang, mulai dari membuat proposal, menciptakan tari yang akan ditampilkan, membuat lagunya, dan melatih guru. Jika akan menciptakan tari massal tingkat Sekolah Dasar, guru-gurunya yang akan mengikuti tari massal dipanggil ke Kota Palembang. Guru-guru tersebut dilatih, setelah gurunya dilatih guru mengajarkan pada muridnya di sekaloh masing-masing. (Wawancara dengan Anna Kumari, di Palembang, 28 Juni 20013).

Anna Kumari mengakui bahwa selama menjadi PNS ia sering dipindah tugaskan. Pertama di Insfeksi Daerah Kebudayaan Kota Palembang, kemudian pindah ke Kator Wilayah. Kemudian Anna Kumari menjadi Penilik Kebudayaan di Kantor Dinas Kebudayaan Kecamatan Seberang Ulu I Palembang, selanjutnya dipindahkan lagi ke Kantor Dinas Pendidikan Kecamatan Ilir Timur II Palembang, Terakhir menjadi Penilik Kebudayaan di seberang Ulu Palembang. Tahun 2005 Anna Kumari pensiun dari Pegawai Negeri Sipil dalam usia 60 tahun.

\section{Menikah dengan Hakky Alian}

Anna Kumari bertemu pertama kali dengan Hakky Alian di Jakarta. Suatu ketika di tahun 1971, Anna Kumari bersama tim kesenian Sumatera Selatan yang tergabung dalam "Teater Subuh" mementaskan drama tradisional "Sang Kedidi dan Sang Buta Turu” di Taman Mini Indonesia Jakarta. Sementara Hakky Alian menjadi anggota DPR-GR Provinsi Sumatera Selatan dari Partai Syarikat Islam Sumatera Selatan. Sebagai anggota dewan daerah Sumatera Selatan, Hakky meninjau tim kesenian daerah Sumatera Selatan yang berkunjung ke Jakarta. Pada saat itulah Anna Kumari pertama kalinya berkenalan dengan Hakky Alian.

Setelah kembali ke Palembang Hakky Alian sering datang ke rumah Anna Kumari, Hakky Alian disampiang ia tamatan IAIN ia juga sama-sama aktif di Partai Syarikat Islam Cabang Palembang dengan Amantjik Rozak. Sebelm berkenalan dengan Anna Kumari Hakky Alian 
sudah sering datang ke rumah Amantjik Rozak untuk berdiskusi masalah-masalah kemasyarakatan maupun organisasi Persatuan Syarikat Islam. Lebih kurang dua tahun Hakky Alian menjalin hubungan dengan Anna Kumari, akhirnya Hakky Alian melamar dan menikahi Anna Kumari.

Hakky Alian yang dilahirkan tahun 1942 meninggal dunia tahun 2002. Dari perkawinannya dengan Hakky Alian, Anna Kumari dikaruniai empat orang anak, yaitu Hanuri Parah Dewi, Mirza Indah Dewi, Muammar Khadafi, paling bungsu Farhan Segentar Alam. Farhan Segintar Alam juga pimpinan Musik Melayu Sanggar "Sigentar Alam”, ia juga punya kemahiran dalam tari Zapin.

\section{Aktivitas Dalam Bidang Seni}

\section{Berjuang Mencari Murid Untuk Menari}

Sekitar tahun 1940 an di Palembang sudah ada tari ronggeng, tidak diketahui dari mana asal tari ronggeng tersebut. Ronggeng adalah "sandiwara keliling", manggung di kampungkampung sampai satu bulan lamanya, para pemainnya menginap di rumah penduduk, mereka berpindah-pindah dari satu kampung ke kampung lain. Dalam ronggeng ada penari sambil berjoget dan pakai saweran, yang nari perempuan dan yang nyawernya laki-laki atau penonton. Penonton juga dibolekan menari, gunanya untuk mencari uang, saat itu kesan terhadap orang penari ronggeng di Palembang sangat jelek.

Karena kesan masyarakat terhadap ronggeng sangat jelek, maka ketika Anna Kumari mengajak anak gadis Palembang untuk belajar menari orang tuanya tidak setuju, mereka beranggapan anaknya akan dibawah untuk belajar menari ronggeng. Anna Kumari kesulitan mencari orang yang mau belajar menari, sehingga Anna Kumari mengajarkan tari hanya di kediamannya. Namun dalam perekembangannya setelah di berikan pengertian pada orang tuanya, akhirnya mereka dapat menerimanya. Kemudian setelah berkembang dan ditambah lagi dengan adanya "Tari Gending Sriwijaya", yang ditarikan oleh oran-orang yang sudah terkenal, maka masyarakat dapat memakluminya. Akhirnya tari dihargai ditambah lagi dalam perkembangannya tari juga dipakai untuk penyambutan tamu-tamu terhormat di Palembang. Murid-murid Anna Kumari yang pertama belajar menari antara lain: Mastura, Maria dan Nurjana. Kemudian muncul yang lainya seperti RA. Saleha dan RA. Yulia (Wawancara dengan Anna Kumari, di Palembang, 29 Juni 2013).

Ketika keberadaan tari sudah melekat di hati masyarakat Palembang, maka diciptakanlah tari “Tepak Keraton”, tari Tepak Keranton ditarikan oleh orang-orang keturunan kereton. Tahun 1965, tari "Gending Sriwijaya" dibekukan dan dilarang ditarikan untuk menyambut tamu agung yang datang ke Palembang. Tari tersebut dibekukan karena ada unsur politik, karena tari "Gending Sriwijaya” diciptakan oleh Nungtjik AR. Tahun1966 an Anna Kumari menciptakan tari "Tepak Keraton", karena alasan politik tari "Gending Sriwijaya" dilarang untuk ditarikan. Tari "Gending Sriwijaya" baru diperbolehkan digelarkan di Sumatera Selatan dengan surat Keputusan Gubernur Sumatera Selatan H. Asnawi Mangku Alam.

Anna Kumari cukup merasa bangga dengan banyaknya bermunculan sanggar-sanggar tari di Sumsel, dulu pertama kali mengajak anak gadis menari mendapat tantangan dari orang tua mereka. Anna Kumari tidak menyerah, setiap hari dia tekun mencari murid door to door ke 
rumah warga. Bahkan bila perlu meminta sejumlah kenalannya untuk mengirimkan anak mereka guna berlatih tari. Semua dilakoninya dengan hati ikhlas dan tampa menuntut imbalan dari para murid. Berket kerja kerasnya, jumlah siswa kian hari kian bertambah. Peminatnya tidak hanya siswa SD, tetapi juga siswa SMP, SMA bahkan mahasiswa. Melihat antusias yang tinggi, Anna Kumari kemudian mulai mengajak para penari untuk pentas diberbagai ajang kebudayaan, baik dalam negeri maupun luar negeri.

\section{Mendirikan Band "Ayam Molek"}

Seiring dengan perjalanan waktu, dimana kreatifvitas Anna Kumari juga berproses. Sekitar tahun 1966 masih muda belia, berawal dari mengasuh sanggar tari "Anna Kumari”, ia mendirikan band wanita yang diberi nama Ayam Molek. Sebelum mendirikan band Ayam Molek Anna Kumari bergabung dengan Orkes Minang Modern Pagaruyung. Band Ayam Molek beranggotakan perempuan semua. Menurut Anna Kumari Band Ayam Molek adalah band perempuan pertama di Pulau Sumatera.

Band Ayam Molek khusus menyanyikan lagu-lagu daerah, dan band ini sering diundang dalam acara-acara pesta pernikahan khususnya di Palembang. Pada saat itu Anna Kumari juga penyanyi Orkes Minang Modern Pagaruyung. Anna Kumari paling suka menyanyikan lagu 'Sikumbang Cari'. Band Ayam Molek sesungguhnya tidak punya alat musik yang memadai, tapi punya kemauan yang keras. Setiap akan tampil, alat alat-alat musik dipinjam sama Orkes Minang Modern Pagaruyung yang pemainnya orang Padang semua.

Band Ayam Molek hanya bertahan lebih kurang tiga tahun, bubarnya Ayam Molek karena Anna Kumari sangat sibuk dan jarang pulang ke rumah, akhirnya ia sering sakit-sakitan, ditambah lagi setiap mau manggung alat musik harus dipinjam terlebih dahulu. Disamping itu setiap malam Anna Kumari harus mengisi acara sebagai bintang radio di RRI Palembang, sehingga Anna Kumari sering sakit-sakitan. Akhirnya suatu ketika Ayahnya bilang "kalau keadaannya seperti ini, kamu harus memilih diantara ke duanya, bukan saya tidak setuju dengan kegiatan kamu, tapi tidak sesuai dengan fisik kamu". Zaman itu Anna Kumari harus kerja siang malam, siangnya main musik, malamnya main teater, kalau kepalanya pusing ia makan bodrek, hampir setiap hari ia lakukan. Anna Kumari berkeyakinan itulah penyebabnya ia kena penyakit leukimia (keracunan obat) yang ia derita sampai sekarang.

\section{Menjadi Bintang Radio di RRI Palembang}

Tahun 1967 Anna Kumari meraih juara 1 bintang radio dibidang lagu Logam Melayu se-Sumatera Selatan. Anna Kumari dikontrak oleh RRI untuk menyanyi di Orkes Studio RRI Palembang khusus menyanyi untuk Logam Melayu. Kontrak Anna Kumari berjalan selagi dapat mempertahankan juara lagu Logam Melayu yang diadakan oleh RRI setiap tahunnya. Anna Kumari dapat mempertahankan juara tersebut selama tiga tahun berturut-turut. Selama dikontrak itulah Anna Kumari harus bernyanyi setiap malamnya di RRI. Antara lain lagu yang sering dinyanyikannya seperti: berpisah, tudung periuk, kuala deli, dan lagu-lagu yang diciptakan oleh pimpinan RRI pada saat itu.

Selain tugas pokoknya bernyanyi, Anna Kumari juga bermain teater, ia sering diundang untuk melatih tari dan teater di sanggar-sanggar tari yang ada khususnya di Kota Palembang. 
Dalam masyarakat Palembang, anak gadis boleh menari ketika masih gadis, kalau sudah bersuami tidak boleh lagi menari. Namun Anna Kumari mengaku walaupun suaminya mengizinkan, namun ia membatasi kegiatan menari, begitu juga dengan teater ia hanya sebagai pelatih dan memberikan pembinaan terhadap sanggar-sanggar yang ada di Kota Palembang.

\section{Penyiar Radio Amatir Samudra Angkatan Laut Palembang}

Tahun 1968 Anna Kumari diminta untuk menjadi penyiar Radio Amatir Samudra Angkatan Laut Palembang. Anna Kumari diminta untuk menjadi penyiar, karena Anna Kumari sudah sangat terkenal pada saat itu. Anna Kumari ditugaskan di Radio Amatir untuk menarik perhatian pemirsa, disamping itu juga untuk menata program dibidang seni. Di Radio Amatir Anna Kumari menata program dibidang seni yang akan diperdengarkan pada khalayak ramai, karena Radio Amatir Angkatan Laut tersebut sebelumnya belum mempunyai program yang tersusun rapi, sebelumnya hanya sebatas nyanyian-nyayian. Anna Kumari yang sudah perpengalaman mengelola program siaran, diminta untuk mengelolah program siaran terutama bagi generasi muda.

Untuk menarik penggemarnya Anna Kumari membuat bermacam-macam program antara lain siaran "Pilihan Pendengar", (meminta lagu pakai kupon). pemirsa/pendengar terlebih dahulu harus membeli dan memesan kupon sebelum lagu diputarkan. Kupon-kupon tersebut dikumpulkan, dan dihitung, bagi pemirsa yang memesan lagu terbanyak maka ia akan mendapat gelar "Ratu Samudra". Ratu akan diundang ke Studio Rama Amatir dan diwawancarai tentang berbagai hal termasuk pendapatnya tentang siaran "Pilihan Pendengar". Dalam perkembanganya siaran "Pilihan Pendengar" ternyata mendapat dukungan yang luar biasa dari penggemarnya. Kemudian dibentuklah organisasi Pengemar Radio Rama Angkatan Laut Palembang.

\section{Guru-Guru Tari dan Musik Anna Kumari}

Watak Anna Kumari menjadi seorang seniman sejati dibentuk oleh orang-orang terdekat di lingkungan keluarga seperti nenek Maryam Dariani (dari pihak ibu), mengajarkan musik harmoni dan gambus serta adat istiadat Palembang. Amantjik Rozak (ayah) mengajarkan main gitar, syair dan puisi. Masnatjik (ibu) mengajarkan dongeng dan pantun. Sedangkan suaminya mengajarkan lagu-lagu dan tari yang bernafaskan Islam. Adapun guru-guru tari dan musik Anna Kumari selain yang disebutkan di atas adalah:

Guru-guru Tari

$\begin{array}{lll}\text { 1. } & \text { Rustam Efendi } & \text { : Tari-tarian daerah Sumsel } \\ \text { 2. } & \text { Iwayan Linggi } & : \text { Tari Bali di Jakarta } \\ \text { 3. Nyoman Suwarning } & : \text { Tari Bali di Istana Merdeka Jakarta } \\ \text { 4. Nyoman Suharniti } & : \text { Tari kerasi Bali dll } \\ \text { 5. Sukaina Rozak } & : \text { Tari Gending Sriwijaya } \\ \text { 6. Cek Aman } & : \text { Tari Qaib } \\ \text { 7. Raden Hamid Ternate } & : \text { Silat Palembang } \\ \text { 8. } & \text { Yulius Toha } & : \text { Tari Sabung }\end{array}$


9. Syap Khaidir : Tari Pergaualan Indonesia di Jakarta

10. Dedi Jaya : Tari Pergaulan di Jakarta

11. Cek Minus : Tari Srempang 12

12. Darussalam : Tari Aceh.

13. J.R. Tanjung : Tari Srempang 12 di Jakarta

Guru-guru dalam bidang musik:
1. J.A. Dungga
: Piano
2. M. Nuh
: Vokal
3. Isak Mahmudin
: Nyanyi
4. Amanan
: Lagu-lagu Melayu
5. E.a Alcaf
: Lagu-lagu pengiring
6. Nurhasan
: Teater dan Tari
7. Wan Ahmad
: mengiringi musik Tari (Catatan Anna Kumari, tanggal 20 Januari 2013).

\section{Tari Ciptaan Anna Kumari}

Tari-tari ciptaan Anna Kumari adalah:

1. Tari Putri Mayang Sari

2. Tari Kipas

29. Sandra Tari Dempo Awang

3. Tari Bebaskan Irian Barat

30. Sandra Tari Nurul Iman

4. Tari Kemboja

31. Sandra Tari Imuk Kuntapati

5. Tari Bayangan Lukisan

32. Tari kmnngn Jayo Ing Sago

6. Tari Sakuntala

33. Fragmenta Sultan Mahmud

7. Tari Bunga Seroja

34. Tari Gadis Tepian Musi

8. Tari Bunga Anggrek

35.Tari Putri Tujuh

9. Tari Kejora

36. Tari Kehume

10. Telaga Sridek

37. Tari Ragam Perca

11. Tari Lenggang Palembang

38. Tari Selendang Mayang

39. Tari Dewi Samudra

12. Tari Saputangan

40. Gadih Lembah Anai

13. Tari Rentak Ria

41. Tari Dewi Sari

14. Tari Selendang Sutra

42. Tari Songket Palembang

15. Tari Rencis-Rencis

16. Tari Putri Dayang Merindu

43. Tari Beras Kunyit

17. Tari Sandang Pangan

44.Tari Rentak Batang Hari 9

18. Tari Tepak Keraton

45. Tari Tepung Tawar

46. Tari Zapin Seberang

19. Tari Kudung Swendek

47. Tari Gema Maha ...

20. Tari Lenggang Kencana

48. Tari Musi Kencana

21. Tari Burung Dara

49. Tari Dian dan Pinggan

22. Tari Indahnya Alam

50. Tari Lilin

23. Tari Bawang Merah, Bawang Putih 
24. Tari Elang Terbang

25. Tari Kumpe Berayun

26. Tari Cek Ingling

27 Tari Mega Mendung

28. Tari Pelangi Senja

\section{c. Aktivitas Dalam Bidang Songket \\ 1. Diawali Dari Koleksi Keluarga}

Aktivitas dibidang tenun songket Palembang bermula dari grup tari. Setiap tampil dalam berbagai acara, grup tari membutuhkan pakaian songket yang tentu saja harus bervariasi. Keluarga Anna Kumari memiliki beberapa potong songket warisan yang cukup tua usianya, harganya juga cukup mahal. Anna Kumari mulai berfikir, jika memakai songket yang asli untuk menari tentu lama kelamaan akan rusak alangkah baiknya jika songket lama itu dimodifikasi, artinya dibuat duplikatnya dengan cara menenun ulang.

Menurut Anna Kumari keturunannya tidak sebagai pengrajin songket, ia hanya pengoleksi songket. Hal itu dilakukan jika anaknya menikah ia harus mengasih songket tujuh turunan (tujuh lembar songket dari berbagai motif), karena keturunan Anna Kumari pelaku adat yang sangat fanatik. Dalam pelaksanaan pernikahan songket sebagai bahan antaran bukan sebagai maharnya. Pemakaian adat yang sangat ketat dikalangan keluarganya, membuat Anna Kumari banyak punya songket lama yang diwarisi dari neneknya. Setiap anak perempuanya menikah ia dapat tujuh potongan songket begitu seterusnya. Songket-songket tersebut diwariskan kepada Anna Kumari. Pemberian songket tujuh turunan hanya berlaku jika perempuan Melayu Palembang menikah dengan jejaka Melayu Palembang.

Jika memakai songket yang asli untuk menari, lama kelamaan akan rusak Berdasarkan pemikiran itulah tahun 1962 an Anna Kumari membuka sanggar yang diberi nama "Kerajinan Songket Anna Kumari”. Sanggar ini membuat songket dengan meniru motif-motif yang ada. Semenjak itu Anna Kumari mulai memproduksi tenun songket Palembang. Tenun songket "Kerajinan Anna Kumari” didirikan di rumahnya yang ia tempati sekarang, sementara sanggar tari di Jl. Kolonel Atmo Palembang. Anna Kumari mengaku semua usahanya bangkrut karena sistem pengelolaannya tidak baik. Karena ia seorang seniman, maka usahanya tidak terkelola dengan baik, lama kelamaan akhirnya mengalami kebangkrutan.

Sanggar "Kerajinan Songket Anna Kumari” sempat punya karyawan sebanyak 50 orang, mereka sebagiannya tinggal di kediaman Anna Kumari. Di tempat tinggalnya Anna Kumari juga membuka kursus tenun songket untuk anak yang putus sekolah, tanpa dipungut biaya. Setelah mereka pandai dan pintar menenun, mereka disuruh berkerja di sanggar-sanggar yang ada khususnya di Kota Palembang. Berkat kesungguhan Anna Kumari dalam mengajarkan tenun pada anak-anak muda Palembang. Tahun 1993 Anna Kumari mendapatkan penghargaan Upakarti dari Presiden Republik Indonesia.

Tahun 1989 produksi "Kerajinan Songket Anna Kumari” telah menembus pasar luar negeri, dengan ikut serta dalam promosi Made in Indonesia Fair di Singapura. Tenun Songket 
Kerajinan Anna Kumari memproduksi songket jenis Prada, Pelangi dan Pelangi Prada. Dalam pameran tersebut beberapa pengusaha asal Kanada dan Brunei Darussalam memesan songket kerajinan Anna Kumari. Harganya saat itu berkisar antara 100 sampai 300 ribu rupiah perlembar. Pengusaha Kanada yang melihat hasil tenunan yang dipamerkan memesan Songket Pelangi sebanyak 200 lembar tiap bulan untuk dipamerkan di Kanada. Sementara pengusaha Brunei Darussalam untuk tahap awal memesan 1 kodi. (Berita Buana, "Untuk Kesejahteraan Rakyat Indonesia" 1989).

Tenun songket Anna Kumari masih berproduksi, namun semenjak tahun 1990-an pekerjaannya dibawa pulang oleh pekerja masing-masing. Lebih kurang 10 orang karyawannya yang mengerjakan tenun di rumah masing-masing. Peralatan disediakan oleh Anna Kumari peralatan tersebut diletakan di rumahnya masing-masing. Modal untuk membeli bahannya juga dikasih oleh Anna Kumari, para pekerja hanya menerima upahnya saja. Untuk menjual hasil produksinya Anna Kumari menyewa tempat di Swalayan "Ramayana Palembang", Anna Kumari memproduksi semua motif songket seperti motif lepus, bunga pacik, limar dll.

\section{Aktivitas Pameran}

Dalam berbagai kesempatan Anna Kumari mempromosikan hasil kerajinan tenunnya baik di dalam negeri mapun ke luar negeri. Hampir lima belas tahun ia mengikuti pameran di berbagai kesempatan. Antara lain pameran Asean di Singapura, pameran Tunggal Songket dari Zaman ke Zaman di Jakarta, pameran Made In Indonesia di Hongkong, di Brunei Darussalam, pameran Salo Exhibition Indonesia di Jedda dan Dubai, pameran di California AS, pameran Konichiwa Asean Fair di Hiroshima Jepang (Catatan Anna Kumari 20 Januari 2013). Berkat usahanya mempromosikan songket asli Palembang ke manca negara, tahun 1993 Sanggar Anna Kumari mendapatkan penghargaan "Upakarti” dari Presiden RI. Sanggar Kerajinan Songket Anna Kumari telah membawa harum nama bangsa Indonesia dan Sumatera Selatan pada khususnya.

Dalam setiap pembukaan pameran, Anna Kumari diberi kesempatan untuk menampilkan tarian daerah yang penarinya adalah para penari "Sanggar Anna Kumari", dengan memakai pakaian songket. Hal ini dimaksudkan supaya para pengunjung dapat mengetahui bahwa songket Palembang tidak kalah menariknya dengan songket dari negara lain. Menurut Wirza Indah Dewi tidak jarang juga orang tuanya sering mengalami kerugian setiap mengadakan pameran, namun karena ia tidak menitik beratkan pada bisnis, akan tetapi lebih menginginkan songket Palembang dapat dikenal di seluruh dunia, sehingga kerajinan tradisional dapat dilestarikan (Wawancara dengan Wirza Indah Dewi, di Palembang, 26 Juni 2013)

\section{Aktivitas Dihari Senja}

Anna Kumari yang sudah diusia senja masih saja tetap berkarya dan beraktivitas. Disamping mengolah Sanggar "Anna Kumari” ia juga melakukan kegiatan penghias pengantin yang tergabung dalam "KATALIA" (Asosiasi Perhias Penganten Modifikasi dan Modern) yang kantornya berpusat di Jakarta dan Anna Kumari sebagai ketua Cabang Provinsi Sumatera Selatan. 
Kegiatan organisasi ini antara lain mengikuti lomba-lomba ditingkat Nasional dan Internasional. Organisasi "KATALIA" di Kota Palembang juga mempunyai cabang. Anna Kumari juga pernah menjadi anggota Dewan Kesenian Provinsi Sumatera Selatan, yang saat itu dijabat oleh Djohan Hanafia. Anna Kumari mengurusi bidang seni tari. Program yang dijalankan antara lain melakukan pembinaan terhadap sanggar-sanggar tari yang ada di kabupaten dan kota dengan cara melakukan pelatihan terhadap anggota-anggotanya.

Anna Kumari juga ketua "HARPI MELATI" (Himpunan Ahli Hias Pengantin Melati) Kota Palembang. Anna Kumari juga melakukan dan membantu acara-acara perkawinan adat masyarakat Melayu Palembang khususnya di lingkungan tempat tinggalnya. Masyarakat masih meminta dan membutuhkan Anna Kumari untuk mengatur segala sesuatunya dalam upacara perkawinan. Anna Kumari sering diminta memimpin upacara perkawinan oleh masyarakat Palembang. Dihari senjanya ia masih membantu melakukan pembinaan terhadap mantan-mantan muridnya yang membuat sanggar-sanggar baik di Kota Palembang maupun di daerah kabupaten dan kota di Provinsi Sumatera Selatan.

\section{Penerima Penghargaan Seni Tahun 2001}

Pamerintah Provinsi Sumatera Selatan melalui Dewan Kesenian Sumatera Selatan telah memberikan Penghargaan Seni kepada 22 orang seniman Sumatera Selatan yang berprestasi dalam kegiatan kesenian atau pembinaan dan pengembangan kesenian di Sumatera Selatan. Salah satu diantaranya adalah Anna Kumari. Anna Kumari menerima penghargaan bidang seni tari. Selain Anna Kumari ada beberapa tokoh daerah Sumatera Selatan yang juga mendapatkan penghargaan pada tahun yang sama dari Gubernur Sumatera Selatan, Eden Arifin, Den Yahya, Anwar Putra Bayu, M. Yasmin Burniat dan Sipan. M. Rohim. (Wawancara dengan Yudhy Sarofie di Palembang, tanggal 27 Juni 2013).

Anna Kumari adalah salah seorang seniman yang konsen dengan masalah kebudayaan khususnya kesenian. Berikut penuturan Anwar Putra Bayu "Kalau saya menilai beliau ini orangnya gigih dan ulet, sampai hari ini sudah tua seperti sekarang, ia masih aktif melakukan kegiatan dibidang seni. Anna Kumari orangnya totalitas, kalau kita minta dia datang kapan saja dia mau datang, dan dia konsen dengan masalah kebudayaan. Dimana-mana ada seminar, loka karya dia kalau diundang pasti datang" (Wawancara dengan Anwar Putra Bayu, di Palembang, 20 September 2013).

\section{Hasrat Yang Belum Terwujud}

Anna Kumari mengaku hasrat hatinya yang belum terwujud diusia senjanya adalah membuat Akademi Tari di Palembang. Anna Kumari berpendapat di Provinsi Sumatera Selatan perlu ada Akademi Tari, sampai sekarang generasi muda yang ingin melanjutkan studinya ke bidang seni tari masih harus pergi ke Sumatera Barat dan daerah lain di Indonesia. Anna Kumari juga punya banyak koleksi dan barang antik di rumahnya. Antara lain berbagai jenis songket lama asli yang sudah berumur ratusan tahun yang diwariskan oleh keluarganya dan masih tersimpan dengan rapi, pedang antik yang juga sudah mulai berkarat. Anna Kumari menginginkan 
rumahnya dipugar untuk dijadikan museum, namun apa daya ia tidak punya modal untuk itu. Anna Kumari juga sudah membuat daftar koleksi yang ia punyai, termasuk songket dan harganya. (Wawancara dengan Farhan Segentar Alam di Palembang, tanggal 28 Juni 2013).

\section{PENUTUP}

Anna Kumari telah menggeluti seni tradisi pertunjukan selama lebih kurang 65 tahun, membuat tokoh ini sangat dikenal pada masanya. Anna Kumari telah dapat menularkan ilmu seninya baik kepada anak-anaknya maupun kepada orang lain. Sampai sekarang banyak muridmurid didikan Anna Kumari yang telah membuat sanggar tari dan menjadi guru tari diberbagai daerah di Provinsi Sumatera Selatan. Berbagai piagam penghargaan yang telah diperoleh oleh Anna Kumari berkat usahanya dalam mengembangkan seni pertunjukan dan pengembangan tenun Songket Palembang. Sampai sekarang diusia senjanya Anna Kumari masih berkarya dibidang seni dan tenun Songket Palembang.

Diharapkan kepada pamerintah khususnya Pemerintah Provinsi Sumatera Selatan adn instansi terkait, jangan hanya sekedar memberikan penghargaan dan ucapan terima kasih kepada para seniman khususnya Anna Kumara yang telah berjasa terhadap perkembangan seni budaya di Palembang, namun yang lebih penting adalah memperhatikan nasib mereka yang sudah memasuki usia lanjut agar mereka para seniman mendapatkan kehidupan yang lebih layak dan terhormat.

\section{DAFTAR PUSTAKA}

\section{BUKU}

Budi Utomo, Bambang, dkk. 2005. Perkembangan Kota Palembang dari Wanua Sriwijaya Menuju Palembang Modern. Palembang: Pemerintah Daerah Kota Palembang. Dinas Pariwisata dan Kebudayaan.

Departemen Kebudayaan dan Pariwisata berkerja sama dengan Asosiasi Tradisi Lisan 2008.. Maestro Seni Tradisi.

Djalili, Ismail dkk, 2003 “Profil 22 Seniman Sumatera Selatan” Penerima Penghargaan Seni (19992002) Dewan Kesenian Sumatera Selatan (DKSS) Provinsi Sumatera Selatan.

Gotschlk, Louis. 1975. Mengerti Sejarah, terj. Nugroho Notosusanto, Jakarta: UI Press.

Hanafiah, Djohan, 1988. Palembang Zaman Bari : Citra Palembang Tempo Doeloe: Humas Paperintah Daerah Tk II Palembang.

........1995. Sejarah Perkembangan Pemerintahan di Daerah Sumatera Selatan. Palembang: Pemerintah Provinsi Tk I Sumatera Selatan.

1995. Melayu - Jawa: Citra Budaya dan Sejarah Palembang, Jakarta: Rajawali.

Irwanto, Dedi dkk. 2010. Dikotomi dan Dinamika Dalam Sejarah Kultural Palembang, Yogyakarta: Eja Publisher.

Kartodirjo, Sartono. 1993. Pendekatan Ilmu Sosial Dalam Metodologi Sejarah, Jakarta: Gramedia. 
Leirissa, R.Z 1984"Segi-Segi Praktis Penulisan Biografi Tokoh” Dalam Pemikiran Biografi dan Kesejarahan : Suatu Kumpulan praseran pada Berbagai Lokakarya, jilid III. Jakarta: Depdikbud, Didjarahnitra, PDSN.

Leonard, Arios Rois dkk.2009 Palembang Buntung, Perjalanan Djhohan Hanafiah Mencari Identitas Budaya Palembang. Laporan Penelitian. Balai Pelestarian Sejarah dan Nilai Tradisional Padang

Syafii, Suadji. 1984 “Menulis Biografi Tokoh” dalam Pemikiran Biografi dan Kesejarahan: Suatu Kumpulan Prasaran Pada Berbagai Lokakarya. Jilid III. Jakarta: Depdikbud. Ditjarahnitra, PIDSN.

Yuanzhi, Kong. 2007. Muslim Tionghoa Cheng Ho (Suntingan Hembing Wijayakusuma), Jakarta. Pustaka Populer Obor.

\section{KORAN}

Berita Buana "Ekonomi \& Keluarga" Kamis 4 Desember 1993

Berita Buana. Untuk Kesejahteraan Indonesia.

Catatan Anna Kumari, tanggal 14 Nopember 2012

Seputar Indonesia, Rabu 17 Desember 2008.

Seputar Indonesia, Rabu 17 Desember 2008.

Sumatera Express, Kamis, 23 Agustus 1990

Sumatera Express, Senin 25 Mei 1998.

Sumatera Pos “Tokoh” Sabtu 16 Mei 2007

\section{WAWANCARA}

Wawancara dengan Anna Kumari, tanggal 24 Oktober 2013 di Palembang Wawancara dengan Farhan Segentar Alam, tanggal 28 Juni 2013 di Palembang Wawancara dengan Putra Bayu, tanggal 20 September 2013 di Palembang Wawancara dengan Yudhy Sarofie, tanggal 27 Juni 2013 di Palembang Wawancara dengan Wirza Indah Dewi, tanggal 27 Juni 2013 di Palembang 